\title{
The Efficiency of a Selective Training Program on the Development of Some Social Skills of Saudi Students with Autism
}

\author{
Ibrahim A. Alothman ${ }^{1}$ \\ ${ }^{1}$ College of Education, King Saud University, Saudi Arabia \\ Correspondence: Special Education Section, College of Education, King Saud University, PrinceTurkey street, \\ Exit 2, Riyadh, Saudi Arabia. Tel: 1467-8720. E-mail: prof.ibrahimalothman@gmail.com
}

Received: October 5, 2015 Accepted: November 16, 2015 Online Published: April 26, 2016

doi:10.5539/ies.v9n5p265 URL: http://dx.doi.org/10.5539/ies.v9n5p265

\begin{abstract}
The objective of the present study is to find out the efficiency of a selective training program on the development of some social skills of Saudi students with Autism. The study sample comprised of (6) male students with Autism who aged (9-12) years, with an average age of (10.58) years, and a standard deviation of (1.16) years. Their IQ ranged on the Stanford-Binet Scale between (67-78) degrees, with an average of (72.17) degrees, and a standard deviation of (4.16) degrees. Their grades on Childhood Autism Rating Scale were between (30-36.5), with an average of (33.67) and a standard deviation of (2.48). The study sample is divided into two groups, one of them is an experimental group that comprised (3) students and the other is a control group that comprised (3) students. The sample also comprised of three teachers of these students. The researcher prepared Social Skills Scale for students with Autism, Childhood Autism Rating Scale translated and revised by Al-Shammri and Al-Sertawi (2003), and a selective training program prepared by the researcher. The results showed that the selective training program which is used in this study was effective on improving the social skills of the Saudi students with Autism.
\end{abstract}

Keywords: Autism, efficiency, development, Saudi, students

\section{Introduction}

Autism is one of the disorders that negatively affect child's development, especially his/her cognitive, social, and emotional development. However, the worst impact of this disorder lies in the child's appearing, before those who are around him, in an inappropriate way from the social viewpoint. This inappropriateness manifests itself either in the deficiencies of communication with others or the difficulty of acquiring the necessary social skills that contribute to build his/her effective social relationships with others.

Autism is a developmental disorder that may be perceived by some researchers as a nervous-developmental disorder that is characterized by deficits in social interactions, language, and repetitive behaviors (Harjusola-Webb \& Robbins, 2012). Other researchers may define Autism according to the hypothetical causes of this disorder. Thus, some of them consider it as a nervous disorder while others see it as a genetic one or as a disorder that is caused by social reasons. Nevertheless, relying on the potential causes in defining this disorder may lead to a lot of shortcomings, especially with the idea that the real causes of this disorder are still not defined yet.

The essential symptoms of the Autism Disorder in children are the difficulties associated with the social interaction and communication capabilities, limited interest in interacting with others, connected and joint attention deficiencies with others as well as poor verbal and non-verbal communication (Casenhiser, Shanker, \& Stieben, 2011). In addition, in spite of the fact that there are children with Autism who enjoy extraordinary abilities in some areas and produce outputs described as serious and original, these children do not often parallel the level of the gifted children with normal growth levels. Pring, Ryder, Crane, and Hermelin (2012) illustrated this point by clarifying that the responses of students with normal growth levels who are artistically gifted (in drawing) are more innovative in terms of fluency, flexibility, and originality than children with Autism who enjoy high capabilities in drawing.

Lerman, Vorndran, Addison, and Kuhn (2004) explained that most teachers receive limited formal education in terms of the evidence-based practices designed particularly for children with Autism. This lack of specialized 
preparation for teachers in the field of Autism in colleges of education leads to the fact that these teachers do not acquire the effective strategies and practices that contribute to improving these children. On the other hand, the effective behavioral strategies, as well as the technological means based on these strategies, are rarely focused on in teacher education programs since the educational system focuses on the theoretical content, rather than on best practices.

To sum up, teachers of students with Autism must work in an educational environment in which families and school systems become strongly connected, especially regarding good educational practices. Many specialists in this field admit that there is a little attention to the most effective practices and methods to work with students with Autism in the educational settings and at college and university levels. Therefore, many teachers are not adequately prepared to effectively teach students with Autism (Morrier, Hess, \& Heflin, 2011).

\subsection{Statement of the Problem}

Social deficiency is among the main problems that children with Autism experience. This is evident in many of behavioral manifestations that indicate weakness in social communication and poor social skills among children with Autism (Bellini \& Hopf, 2007; Murdock, Cost, \& Tieso, 2007). The social skills of students with Autism are among the fundamental objectives of many effective programs based on many of the strategies that take into account the characteristics of these students at the cognitive and social levels. The caregivers of these students, especially parents and teachers, are entitled to apply these strategies since they interact more with the child and are more familiar with the characteristics of the child in the natural environmental conditions. Hence, specialists in the field of Autism heavily expressed the dire need for training parents and teachers on the most effective strategies to improve the cases of children with Autism, which led to the so-called Parent Education Programs and Teacher Education Programs. These programs changed the parents' perception from being mere sources of information to being professionals in the application of the strategies and programs dedicated to children with Autism. In addition to changing teachers from being teachers of a range of theoretical information, which is useless in dealing with students with Autism, to the fact that they are well-aware of methods of preparing and applying the effective programs and strategies that take into account the cognitive and social characteristics of these students.

The researcher of the current study noticed that teachers of children with Autism in Saudi Arabia did not include evidence-based practices in their teaching programs of students with Autism even they learnt these strategies during their studying period in college. This is due to many teachers' conviction that they did not receive adequate training on the use of these practices. These teachers need Self-preparation programs after graduation to prepare them for the real experience with students with Autism. Consequently, he tried to find out the efficiency of a selective training program on the development of some social skills of Saudi students with Autism. This main question leads to thinking about answers of the following sub-questions:

1) Are there any significant differences between the scores of the experimental group and those of the control group on the Social Skills Scale (SSS) after the application of the program?

2) Are there any significant differences between the scores of the students with Autism in the experimental group on the SSS pre- and post measurements?

3) Are there any significant differences between the scores of the students with Autism in the experimental group on the SSS in post and the follow-up measurements?

\subsection{Objective of the Study}

The present study tried to find out the efficiency of a selective training program on the development of some social skills of Saudi students with Autism.

\subsection{Significance of the Study}

With the increasing numbers of children with Autism, there has become an urgent need to search for effective strategies and methods for developing the capabilities of these children and reducing the behavioral problems they suffer. In order to help children with Autism to increase their communication and social interaction with those around them whether at home or school, teacher education programs of effective strategies in the field of educating and improving the cases of children with Autism became the bases for any effective educational program.

Theoretically, the current study is important since it sheds light on the effective strategies in training programs that teachers of students with Autism need in order to improve the cases of these students with Autism as one of the groups whose numbers are increasing in the community. Moreover, this study presents several successful 
examples of some effective strategies that proved, by a number of studies from all over the world in terms of training teacher to use these strategies in developing social, communicative, connected attention and playing skills among children with Autism.

On the other hand, the applied significance of the present research lies in presenting an attempt to train teachers of some students with Autism to apply some of the techniques of effective strategies in the field of Autism and to identify the impact of the application of these techniques in the development of some social skills among those students.

\subsection{Terms of the Study}

Teachers of Children with Autism: A teacher in the field of special education is entitled with a noble mission and message. $\mathrm{S} / \mathrm{he}$ is entrusted with the students and is responsible for their upbringing in a way that achieves the objectives of the education policy in the Kingdom. Teachers of students with Autism are defined-procedurallyas a category of teachers who provide services to those students at the Institute of Intellectual Education, East of Riyadh.

A Selective Training Program: A set of regulatory measures that are planned, followed, and based on some effective strategies to improve the cases of children with Autism. The training program of the present study is defined-procedurally-in two ways: the first one: the training conducted by the researcher to a sample of teachers of students with Autism to use some of the techniques found in the natural communication strategies and social stories in order to develop some social skills among a sample of students with Autism. Second; the sample of teachers of students with Autism who had been trained for a series of training sessions that are based on the use of some of the natural communication strategies and social stories for the development of some social skills among a sample of those students.

Natural Communication Strategies: Strategies based on the provision of educational opportunities and interactive responses as a necessary part of the learning process, as well as the use of the natural environment as an educational context. They are based on the application of evidence-based practices within the normal environment of the child.

Social Stories: a strategy based on the use of brief stories that describe a social situation and present effective behavioral responses that are appropriate for social situations through sentences that: reflect specific situations, written according to clear rules, supported by visual stimulus, and providing answers about: (Who, What, When, Where, and Why). This strategy is assisted by a number of behavioral techniques, especially prompting, verbal stimulation, modeling, role playing, training, feedback, homework, and teaching. They are defined-procedurally-as sessions of the program based on the use of social stories and the content of some techniques used in their application.

Social Skills: performance behaviors that are effective and functional in the context of social settings and take into account the psychological, cognitive, and behavioral status of the others. They agree with the social standards that define positive and negative behaviors, as well as attain an objective of making the individual an effective element able to fulfill the cognitive, social, and emotional needs in a way that makes others' accept and praise of his/her behavior. Social skills are defined-procedurally-by the scores obtained by the child with Autism in the Social Skills Scale SSS (prepared by the researcher).

Autism Disorder: a developmental disorder that negatively affects-the aspects of a child's growth, especially the cognitive, social, and emotional growth. It usually affects the child before reaching the age of three. The affected child develops the symptoms of this disorder, particularly deficiencies in communication, social interaction, and restricted/repetitive behaviors; early detection of this disorder is necessary to provide early intervention services, especially since causes of this disorder are not agreed-on among scientists in this field. Students with Autism are defined-procedurally-as some of the students with Autism at the Institute of Intellectual Education, east of Riyadh.

\section{Literature Review and Theoretical Framework}

\subsection{The Selective Training Programs}

\subsubsection{Natural Communication Interventions}

The interests and characteristics of the child as well as the appropriate interventions from the developmental viewpoint are preliminary considerations for using various strategies for developing communication among children with Autism. Teachers of these children often design individual educational plans based on the current level of the child's functioning, interests, and priorities. The best communication development programs 
provided for these children depend on interventions that are designed in the natural environment of the child such as social stories, time-delay, milieu language teaching, and natural language paradigm (Harjusola-Webb \& Robbins, 2012).

This was established by Harjusola-Webb and Robbins's (2012) study that attempted to clarify the effects of the training program of teachers based on natural interventions for the development of communication among three children with Autism in preschool stage. It also attempted to provide information about the means of supporting positive communicative and social relations among children and adults through the introduction of the noninvasive strategies in the context of natural environments. In this study, the teachers received training and support in the application of strategies for the development of natural communication in order to increase the opportunities of expressive communication for the child. As a result of this training, the teachers' use of intervention strategies increased and all the children in the study sample showed increases in the frequency of expressive communication. The findings confirmed the significance of the linguistic approach, the effect of the level of intervention, and the repetition by the teacher for the communication opportunities on the communicative behavior of the child.

Natural communication interventions increase the quality and quantity of interactions among adults and children across environments. Interactions among children and adults are positively affected through teaching adults responsiveness and conversational strategies to be used with children (Horn, Lieber, Sandall, \& Schwartz, 2001).

Walker, Harjusola-Webb, Bigelow, Small, and Kirk (2004) applied intervention for teacher training on the use of intervention strategies in the classroom. The training on intervention included three main components: the list of intervention strategies, continuous interviews with researchers, and feedback on performance. It was found that the teacher training model is effective in increasing information for the purpose of practicing, teacher's application of the intervention strategies, and the child's communication in the community merging conditions.

Casenhiser, Shanker, and Stieben's (2011) study aimed at assessing the strengths and weaknesses of the child's speech and communication as well as cognitive, sensory, and motor capabilities, and teaching parents about the strengths and weaknesses of their children and identify strategies that are appropriate for the child and the family. In addition to the weekly interviews, caregivers had sessions with therapists nearly every eight weeks to discuss progress and review the videotape of the play sessions of the caregivers and the child in order to get a clear vision of a special manner of treatment and to answer any questions that could be posed during the weekly sessions. The study sample comprised 51 children suffering from Autism.

Casenhiser, Shanker, and Stieben's (2011) study focused on four aspects of social communication. First, the quality of social interaction through clarifying the way a child is connected to playing. Second, the child's ability to engage in and start connected attention models. Third, the degree of child's enjoyment of the interaction with the caregiver, which well-reflects the intrinsic motivation of a child to interact with adults. Fourth, social interaction is the primary means by which children learn language more typically.

Among the programs that aim at improving the capabilities of interaction and social communication among children, and is also concerned with the natural context of the child, is the (MEHRIT) treatment program, which includes all the characteristics of the developmental, social, and pragmatic interventions (Casenhiser, Shanker, \& Stieben, 2011). MEHRIT is based on many of the developmental capabilities that are derived from the Developmental Individual-difference Relationship-based Model (DIR) designed by (Greenspan, Wieder, Hollander, and Anagnostou, 2007), which, in its basis, is a guide to treatment. This model is based on the fundamental idea that the degree of functionality of late capabilities depends on the degree of functionality of early capabilities.

Pivotal Response Training (PRT) is also one of the educational practices that are effective for teaching students with Autism. It is a natural behavioral intervention that has been developed to facilitate generalization, increasing spontaneous interaction, reducing dependence on immediate prompts, and increasing the motivation of students with Autism. Stahmer (2007) showed that more than $70 \%$ to $80 \%$ of the teachers in the southern province of California are using PRT programs. Since PRT has been developed for the use in the natural environment, the classroom is an appropriate context for the application of PRT (Suhrheinrich, 2011).

\subsection{Social Stories}

A social story is among the strategies that many of the studies proved its effectiveness in developing social skills and social communication among children with Autism. Social stories contribute to educating "children with developmental disorders" the appropriate social behaviors and interactions as well as better performance in the classroom through the use of pictures and symbols with short sentences in the form of a small book (Hagiwara \& 
Myles, 1999).

Scattone, Wilczynski, Edwards, and Rabian (2002) illustrate that social stories is a visual learning strategy in the form of short stories that introduce social situations and specify the correct responses in these situations. These stories provide children with Autism with proper social information in terms of: where and when the situation occurs, who the persons in the situation are, what is happening during this situation, and why this situation occurs

Ivey, Heflin, and Alberto (2004) illustrate that social stories describe the components of social situations and provide the expected responses. Social stories do not teach social skills only, but also contribute to the identification of the expected behaviors within the environment in which the child reacts. A social story is, therefore, an effective behavioral intervention to improve the cases of children with Autism. They are short stories written in a simple style and derived from the child's environment to teach positive behaviors that help him interact positively with the medium in which s/he lives (Crozier \& Sileo, 2005).

Gray (2002) emphasizes that the applied significance of social stories is reflected in the fact that they translate the educational goals into easy-to-understand steps. They also contribute to supplying a steady and consistent audio-visual model for behavioral responses, work on the preparation of the unexpected situations, and underline performance and achievement. There is a set of basic steps that must be followed in order to effectively use social stories, which are: identifying and defining the target behavior, managing the child's performance assessment, preparing a plan to include social stories, writing social stories, using social stories with the child, and data collection (Crozier \& Sileo, 2005).

\subsubsection{Social Skills among Children with Autism}

Social skills among children are a translation for normal growth of the child on a social level, since they are the basis for the child in expressing himself/herself and his/her requirements in the social environment in which s/he lives as well as the paved way for giving the child the feeling that $\mathrm{s} /$ he is an integral part of the social context in which s/he lives- an environment that affects them and is affected by them. They are also an evidence of the normal cognitive development of the child.

Developing social skills among students with Autism is one of the fundamental objectives of many training and treatment programs provided to these students, and the application of which may be undertaken by teachers in the school environment in which these students spend a long time. Therefore, the researcher reviewed some of the studies that dealt with the training of teachers of students with Autism on the application of some techniques found in some strategies which studies have proved effective in improving the cases of children with Autism. The following is a review of relevant studies.

Howell's (2005) study focused on assessing whether the social stories of Carol and Gray and comic talks are still effective interventions in the classroom. Surveys of teachers who assessed the use and effectiveness of social stories and comic talks within classrooms were conducted. The study sample comprised 90 teachers of students with Autism in pre-school, primary, basic, and high stages. Findings showed that social stories are used by many teachers and have been assessed as an effective strategy. Comic talks, on the other hand, are used by $15 \%$ of the sample of the study but are also assessed as effective.

Chan's (2009) study examined the use of social stories with students with Autism in inclusion settings in public education in order to improve some behaviors among these students, such as: challenging, screaming, confusion, and beating. Social stories were introduced on a personal computer to five out of the six students, while social stories were introduced to the sixth student in a book. Findings showed improvements in the target behaviors of five out of the six students.

Morrier, Hess, and Heflin's (2011) study discussed the training programs received by teachers of students with Autism in one of the USA states. $15 \%$ of the study sample, 90 teachers, said they had been trained in teacher training programs at colleges or universities, but they pointed out that the types of training they received do not focus on the use of evidence-based practices. Findings showed that teachers receive training from more than one source, including cooperation with the parents of children with Autism and that pre-service and in-service teachers need to be trained on using the evidence-based practices identified for these children.

Leaf, Oppenheim-Leaf, Call, Sheldon, and Sherman's (2012) study attempted a comparison between social stories and interactive teaching procedures in teaching social skills to six children with Autism. The researchers taught these children 18 social skills using social stories and other 18 social skills using interactive teaching procedures. Findings showed the effectiveness of social stories and interactive teaching procedures in the development of social skills among children with Autism. 


\section{Method}

\subsection{Methodology of the Study}

The researcher of the current study adopted a quasi-experimental approach in the formation of a single group design. He conducted the pre, post, and follow-up assessments of the scores of the sample of the study on the SSS.

\subsection{Hypotheses}

The following hypotheses were formulated as possible answers to the questions posed in the problem of the study:

1) There are statistically-significant differences between the average scores of the experimental and control groups on the SSS after the application of the program in favor of the experimental group.

2) There are statistically-significant differences between the scores of the experimental group on the SSS in the pre and posttests, in favor of the posttest.

3) There are no statistically-significant differences between the scores of the experimental group on the SSS in the pre and post and follow-up tests.

\subsection{Sample}

The sample of the present study include students with Autism and their teachers from the Institute of Intellectual Education, east of Riyadh-Saudi Arabia, where there is a large number of children with Autism as well as many of the resources necessary to apply the program of study. The sample comprised (6) male students with Autism who achieved low scores on the SSS, aged 9-12 years, with an average age of (10.58) years and a standard deviation of 1.16 years. Their IQ scores on Stanford-Binet scale ranged between (67-78) degrees, with an average of (72.17) degrees and a standard deviation of (4.16) degrees. The study sample was divided into two groups, one of them is an experimental group that includes (3) students, and the other is a control group that includes (3) students. The individuals of the sample were diagnosed with low and average Autism after they achieved scores ranging between (30-36.5), with an average of (33.67) degrees and a standard deviation of (2.48) degrees on the Childhood Autism Rating Scale. Table 1 illustrates this equivalence.

Table 1. Mann-Whitney (U) test results for the detection of equivalence between the experimental and the control group of the pilot study sample

\begin{tabular}{lccccccc}
\hline \multirow{2}{*}{ Variables } & Group & No. & $\begin{array}{c}\text { Average } \\
\text { Scores }\end{array}$ & $\begin{array}{c}\text { Total } \\
\text { Scores }\end{array}$ & U & Z & Significance \\
\hline \multirow{2}{*}{ Age (in months) } & Experimental & 3 & 3.33 & 10 & & -- & Insignificant \\
& Control & 3 & 3.67 & 11 & & .218 & \\
IQ & Experimental & 3 & 4 & 12 & & -- & Insignificant \\
& Control & 3 & 3 & 9 & & .655 & \\
Autism Degree & Experimental & 3 & 3.67 & 11 & & -- & Insignificant \\
& Control & 3 & 3.33 & 10 & 4 & .218 & \\
Social Skills & Experimental & 3 & 3.33 & 10 & 4 & -- & Insignificant \\
& Control & 3 & 3.67 & 11 & & .218 & \\
\hline
\end{tabular}

Table 1 shows that there are no statistically significant differences between the average scores of the two groups, the experimental and control groups, in terms of age, IQ, Autism degree, and social skills.

\subsection{Tools}

In order to achieve the objectives of the present study, the researcher used the following tools:

1) The Social Skills Scale for Students with Autism (Designed by the Researcher):

To conclude the final version of the scale, the researcher determined the psychometric properties of the scale. These were as follows:

Reliability of the Scale: the researcher verified the reliability of the scale in several ways: 
Raters Reliability: the researcher introduced the initial scale to a group of respected raters-professors in the field of special education-in order to judge the scale in terms of the clarity of statements, soundness of their formulation, affiliation of each phrase to its own dimension, modifying any phrase that needs modification, and adding any proposed phrases. The phrases that achieved at least $90 \%$ of the consensus of the raters, and as a result, the researcher deleted two phrases and the final number of the scale phrases was 60 phrases, falling under two dimensions as follows: social engagement that includes (30) phrases and social communication that includes (30) phrases. Table 2 identifies the SSS phrases and the percentages of arbitrators' agreement on each phrase:

Table 2. Percentages of Arbitrators' agreement on the scale phrases

\begin{tabular}{|c|c|c|c|c|c|}
\hline \multicolumn{2}{|c|}{ The First Dimension (Social Engagement) } & \multicolumn{4}{|c|}{ The Second Dimension (Social Communication } \\
\hline$\dot{\mathrm{z}}$ & The Phrase & 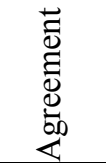 & $\dot{z}$ & The Phrase & 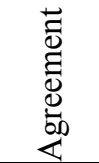 \\
\hline 1 & $\begin{array}{l}\text { Avoids social situations with other } \\
\text { students }\end{array}$ & $100 \%$ & 1 & Communicates non-verbally with others & $100 \%$ \\
\hline 2 & $\begin{array}{l}\text { Shows tantrums when things do not } \\
\text { go as s/he wants }\end{array}$ & $99 \%$ & 2 & $\begin{array}{l}\text { Joins social activities without being } \\
\text { asked to }\end{array}$ & $100 \%$ \\
\hline 3 & Accepts other children & $100 \%$ & 3 & Avoids physical contact with others & $100 \%$ \\
\hline 4 & Tends to be away of others & $100 \%$ & 4 & Cooperative during activities & $100 \%$ \\
\hline 5 & His/her temper changes rapidly & $100 \%$ & 5 & Take turns in playing with others & $100 \%$ \\
\hline 6 & $\begin{array}{l}\text { Can express in an emotional way that } \\
\text { suits the situation }\end{array}$ & $100 \%$ & 6 & Cooperates with peers during play-time & $100 \%$ \\
\hline 7 & Keeps participating in playing & $100 \%$ & 7 & $\begin{array}{l}\text { His/her behaviors are in line with } \\
\text { his/her interactions with others }\end{array}$ & $100 \%$ \\
\hline 8 & $\begin{array}{l}\text { Gets nervous when s/he cannot } \\
\text { predict the environment }\end{array}$ & $100 \%$ & 8 & $\begin{array}{l}\text { Approaches and sympathizes with } \\
\text { others }\end{array}$ & $100 \%$ \\
\hline 9 & Starts playing with others & $100 \%$ & 9 & Approaches and plays with others & $100 \%$ \\
\hline 10 & $\begin{array}{l}\text { Responds to new ideas and } \\
\text { suggestions }\end{array}$ & $100 \%$ & 10 & Starts activities with others & $100 \%$ \\
\hline 11 & Responds to direct education & $100 \%$ & 11 & Starts greeting others & $100 \%$ \\
\hline 12 & Takes turns in interacting with others & $100 \%$ & 12 & Engages with others in playing & $100 \%$ \\
\hline 13 & Asks for help and guidance & $100 \%$ & 13 & Does as required & $100 \%$ \\
\hline 14 & Avoids eye-contact & $100 \%$ & 14 & Plays near to others & $99 \%$ \\
\hline 15 & Easy-to-guide & $100 \%$ & 15 & $\begin{array}{l}\text { Shows attention to others around } \\
\text { him/her }\end{array}$ & $100 \%$ \\
\hline 16 & $\begin{array}{l}\text { His/her emotional behavior is } \\
\text { appropriate }\end{array}$ & $98 \%$ & 16 & Approaches and asks to play with others & $100 \%$ \\
\hline 17 & Understands rules of plays & $100 \%$ & 17 & Participates in playing with others & $100 \%$ \\
\hline 18 & Looks at what others are looking at & $100 \%$ & 18 & $\begin{array}{l}\text { Engages in bilateral interactions with } \\
\text { others }\end{array}$ & $100 \%$ \\
\hline 19 & $\begin{array}{l}\text { Participate with his/her peers in } \\
\text { shifting sight among things }\end{array}$ & $100 \%$ & 19 & Avoids interaction with peer groups & $100 \%$ \\
\hline 20 & $\begin{array}{l}\text { Looks at the eyes of others when they } \\
\text { talk to him/her }\end{array}$ & $100 \%$ & 20 & Uses appropriate signals for interaction & $100 \%$ \\
\hline 21 & Responds to the teacher's requests & $100 \%$ & 21 & Looks at whoever calls his/her name & $100 \%$ \\
\hline 22 & Be side-by-side with other children & $100 \%$ & 22 & Can use a sentence in its correct context & $100 \%$ \\
\hline
\end{tabular}




\begin{tabular}{|c|c|c|c|c|c|}
\hline 23 & $\begin{array}{l}\text { Responds to others with verbal } \\
\text { initiatives }\end{array}$ & $100 \%$ & 23 & Thanks others for providing help & $100 \%$ \\
\hline 24 & $\begin{array}{l}\text { Moves easily from one activity to } \\
\text { another }\end{array}$ & $99 \%$ & 24 & peers to listen to their talks & $100 \%$ \\
\hline 25 & $\begin{array}{l}\text { Enjoys a number of activities and } \\
\text { plays }\end{array}$ & $100 \%$ & 25 & Starts approaching others & $100 \%$ \\
\hline 26 & $\begin{array}{l}\text { Automatically responds to peers' } \\
\text { requests }\end{array}$ & $100 \%$ & 26 & $\begin{array}{l}\text { Engages in social behaviors, such as } \\
\text { greeting peers }\end{array}$ & $100 \%$ \\
\hline 27 & $\begin{array}{l}\text { Pay attention to others' participation } \\
\text { with him/her }\end{array}$ & $100 \%$ & 27 & $\begin{array}{l}\text { Waves his/her hands to others as a } \\
\text { greeting }\end{array}$ & $100 \%$ \\
\hline 28 & $\begin{array}{l}\text { ift his/her sight among more } \\
\text { e stimulus }\end{array}$ & $100 \%$ & 28 & Shows awareness of others & $85 \%$ \\
\hline 29 & $\begin{array}{l}\text { Shifts his/her sight among individuals } \\
\text { and things }\end{array}$ & $100 \%$ & 29 & $\begin{array}{l}\text { Responds with "YES" when being } \\
\text { called }\end{array}$ & $95 \%$ \\
\hline 30 & $\begin{array}{l}\text { Looks at his/her peers and utters } \\
\text { some understandable words }\end{array}$ & $100 \%$ & 30 & Responds to others' greeting to him/her & $100 \%$ \\
\hline 31 & $\begin{array}{l}\text { Goes away from others during } \\
\text { practicing activities }\end{array}$ & $80 \%$ & 31 & Follows the instructions of the teacher & $100 \%$ \\
\hline
\end{tabular}

After identifying the initial version of the phrases of the scale, the researcher determined the response system to these phrases as well as the key answers. This was as follows: Each phrase has three choices (often, sometimes, and rarely). The answer that signifies the full social skill has "three marks", the answer that signifies an approach to the social skill has "two marks", and the answer that signifies the lack of social skill has "one mark". There are some statements that are corrected in reverse. Thus, the total score in the first dimension is (90) and in the second is (90) while the total score of the scale as a whole is (180). Thus, the total score ranges, for the child on the scale, between (60) and (180).

Concurrent Validity (Criterion): the researcher calculated the correlation coefficient, using Pearson's method, between the marks of the standardization sample which amounted to (25) teachers of students with Autism and the Social Interactions Scale as an external factor. The value of the correlation coefficient was (93), which is significant at the level (.01)

Validity of the Peripheral Comparison: the researcher calculated the validity of the scale using the peripheral comparison (Validity of Differentiation) using the Mann-Whitney (U) test in order to find the significance of differences between the averages of scores of the small independent group. The findings showed the presence of a statistically-significant difference between the averages of the estimating degrees of the teachers at the highest level and the estimating degrees of the teachers at the lowest level, in the direction of the highest level. Thus, the scale has a strong validity of differentiation.

Validity of the Scale: the researcher verified the constancy of the scale in several ways:

1) Re-applying the Scale: The stability of the scale coefficient was $(0.78)$ which is statistically-significant at the level of (.01).

\section{2) Reliability of the Internal Consistency of the Scale:}

The researcher calculated the internal consistency of the scale by:

Calculating the correlation coefficients between the marks of every single phrase of the scale and the total score of the scale. Table 3 shows the findings of this procedure: 
Table 3. The correlation coefficients between the degree of each phrase of the SSS and the total degree of the scale

\begin{tabular}{llllllll}
\hline Social Engagement & & & Social Communication & \\
\hline No. & $\begin{array}{l}\text { Correlation } \\
\text { Coefficient }\end{array}$ & No. $\begin{array}{l}\text { Correlation } \\
\text { Coefficient }\end{array}$ & No. $\begin{array}{l}\text { Correlation } \\
\text { Coefficient }\end{array}$ & No. & $\begin{array}{l}\text { Correlation } \\
\text { Coefficient }\end{array}$ \\
\hline 1 & $* * .635$ & 16 & $* * .546$ & 1 & $* * .724$ & 16 & $* * .552$ \\
2 & $* * .562$ & 17 & $* * .775$ & 2 & $* * .615$ & 17 & $* * .622$ \\
3 & $* * .589$ & 18 & $* * .698$ & 3 & $* * .623$ & 18 & $* * .458$ \\
4 & $* * .725$ & 19 & $* * .558$ & 4 & $* * .479$ & 19 & $* * .563$ \\
5 & $* * .796$ & 20 & $* * .659$ & 5 & $* * .586$ & 20 & $* * .658$ \\
6 & $* * .567$ & 21 & $* * .488$ & 6 & $* * .468$ & 21 & $* * .732$ \\
7 & $* * .744$ & 22 & $* * .598$ & 7 & $* * .566$ & 22 & $* * .564$ \\
8 & $* * .635$ & 23 & $* * .659$ & 8 & $* * .671$ & 23 & $* * .658$ \\
9 & $* * .555$ & 24 & $* * .678$ & 9 & $* * .420$ & 24 & $* * .765$ \\
10 & $* * .658$ & 25 & $* * .758$ & 10 & $* * .714$ & 25 & $* * .462$ \\
11 & $* * .558$ & 26 & $* * .685$ & 11 & $* * .518$ & 26 & $* * .554$ \\
12 & $* * .563$ & 27 & $* * .633$ & 12 & $* * .653$ & 27 & $* * .754$ \\
13 & $* * .757$ & 28 & $* * .705$ & 13 & $* * .563$ & 28 & $* * .625$ \\
14 & $* * .784$ & 29 & $* * .618$ & 14 & $* * .709$ & 29 & $* * .489$ \\
15 & $* * .590$ & 30 & $* * .534$ & 15 & $* * .524$ & 30 & $* * .657$ \\
\hline
\end{tabular}

**Significant at: 0.01 .

Table 3 shows the correlation coefficients between the degrees of each phrase of the SSS and the total degree of the scale that stresses the stability of the scale phrases.

Calculating the correlation coefficients between the degree of each dimension of the scale and the total degree of the scale. Table 4 shows the findings of this procedures:

Table 4. Correlation coefficients between the degree of each dimension of the SSS and the total degree of the scale

\begin{tabular}{ll}
\hline Dimension & Correlation Coefficient \\
\hline Social Engagement & $* * .623$ \\
Social Communication & $* * .615$ \\
\hline
\end{tabular}

** Significant at: 0.01 .

Table 4 shows the correlation coefficients between the degree of each dimension of the SSS and the total score of the scale that is significant at (.01); which indicates the reliability of the scale dimensions.

Childhood Autism Rating Scale, translated and refined by Al-Shammari and Al-Sertawi (2003):

The Childhood Autism Rating Scale, which includes fifteen domains of behavioral rating, was developed to identify children with Autism and to differentiate between them and children who suffer from developmental disabilities without suffering from Autism(Al-Shammri, Al-Sertawi, and Qaraqish, 2010). Children whose scores are below (30) are not classified in the category of Autism, while those whose scores are at (30) or more are classified as autistic.

The Selective Training Program (designed by the researcher):

The program aims at developing some social skills among students with Autism through the application of the teachers of these students to a selective training program that is based on the use of certain techniques of natural 
communication and social stories. The researcher designed the program sessions according to the applied foundations of some techniques of natural communication and social stories. He divided the program sessions into two axes. The first axis: Training the sample of the study of the teachers of students with Autism on the use of some techniques of the natural communication strategies and social stories. The second axis: the application of the sample that has been training of the teachers of students with Autism to a series of training sessions based on the use of certain natural communication strategies and social stories in order to develop some of the social skills among a sample of these students. The first training sessions were divided into (20) sessions that are further divided into four weeks, five weekly sessions. The duration of each session ranged between (60-90) minutes. The second training sessions were divided into (30) sessions that further divided into six weeks, five weekly sessions. The duration of each session ranged between (60-90 minutes).

Rating of the Program:

The researcher presented the program, in its initial version to a group of special education professors for the purpose of rating in terms of its significance, clarity of objectives, nature and number of its sessions, the content of its sessions and activities, and the means used. The researcher made some amendments noted by the arbitrators.

Application of the Program:

The program was applied to three children with Autism (the experimental sample) at the Institute of Intellectual Education in eastern Riyadh, during the first semester of the academic year 2014-2015.

\section{Findings}

\subsection{Findings of the First Hypothesis}

The first hypothesis stated that: "there are statistically-significant differences between the average scores of the experimental and control groups on the SSS after the application of the program, in favor of the experimental group." To validate this hypothesis, the researcher used Mann-Whitney Test to identify the significant differences between the averages of the scores ranks of the small independent groups. Table (5) shows the findings of this procedure:

Table 5. Mann-Whitney tests findings for the detection of significant differences between the scores' ranks of the experimental and control groups on the SSS after the application of the program

\begin{tabular}{|c|c|c|c|c|c|c|c|}
\hline \multirow[b]{2}{*}{ SSS } & \multicolumn{2}{|c|}{$\begin{array}{l}\text { The Experimental } \\
\text { Group. }(\mathrm{No}=3)\end{array}$} & \multicolumn{2}{|c|}{$\begin{array}{l}\text { The Control } \\
\text { Group. }(\mathrm{No}=3)\end{array}$} & \multirow[b]{2}{*}{$\mathrm{U}$} & \multirow{2}{*}{$\begin{array}{c}Z \\
\text { Value }\end{array}$} & \multirow[b]{2}{*}{ Significance } \\
\hline & $\begin{array}{l}\text { Average } \\
\text { of Ranks }\end{array}$ & $\begin{array}{c}\text { Total } \\
\text { Ranks }\end{array}$ & $\begin{array}{l}\text { Average } \\
\text { of } \\
\text { Ranks }\end{array}$ & $\begin{array}{c}\text { Total } \\
\text { Ranks }\end{array}$ & & & \\
\hline After Social Engagement & 5 & 15 & 2 & 6 & Zero & $1.993-$ & .01 \\
\hline After Social Communication & 5 & 15 & 2 & 6 & Zero & $1.964-$ & .01 \\
\hline Total Degree & 5 & 15 & 2 & 6 & Zero & $1.964-$ & .01 \\
\hline
\end{tabular}

Table 5 shows statistically-significant differences at (.01) between the averages of scores ranks between the experimental and control groups on the SSS and its sub-dimensions after the application of the program in favor of the experimental group, which validates the first hypothesis.

\subsection{Findings of the Second Hypothesis}

The second hypothesis stated that "there are statistically-significant differences between the scores of the experimental group on the SSS in the pre and posttests, in favor of the post test." To validate this hypothesis, the researcher used Wilcoxon (W) Test to detect the significant differences between the scores ranks of the small groups. Table 6 shows the findings of this procedure: 
Table 6. Wilcoxon (W) test for the detection of significant differences between the averages of scores ranks of the experimental group in pre-post tests on the SSS

\begin{tabular}{|c|c|c|c|c|c|c|}
\hline SSS & $\begin{array}{l}\text { The Pre and Post } \\
\text { Measurement }\end{array}$ & No. & $\begin{array}{c}\text { Average of } \\
\text { Ranks }\end{array}$ & $\begin{array}{c}\text { Total } \\
\text { Ranks }\end{array}$ & $\begin{array}{c}Z \\
\text { Value }\end{array}$ & Significan \\
\hline \multirow{4}{*}{ After Social Engagement } & Negative Ranks & Zero & & & \multirow{4}{*}{$1.604-$} & \multirow{4}{*}{.01} \\
\hline & Positive Ranks & 3 & Zero & Zero & & \\
\hline & Equivalence & Zero & 2 & 6 & & \\
\hline & Total & 3 & & & & \\
\hline \multirow{4}{*}{$\begin{array}{l}\text { After } \\
\text { Communication }\end{array}$} & Negative Ranks & Zero & & & \multirow{4}{*}{$1.633-$} & \multirow{4}{*}{.01} \\
\hline & Positive Ranks & 3 & Zero & Zero & & \\
\hline & Equivalence & Zero & 2 & 6 & & \\
\hline & Total & 3 & & & & \\
\hline \multirow{4}{*}{ Total Degree } & Negative Ranks & Zero & & & \multirow{4}{*}{$1.604-$} & \multirow{4}{*}{.01} \\
\hline & Positive Ranks & 3 & Zero & Zero & & \\
\hline & Equivalence & Zero & 2 & 6 & & \\
\hline & Total & 3 & & & & \\
\hline
\end{tabular}

Table 6 shows statistically-significant differences at (.01) between the averages of scores ranks of the experimental group in the pre and post measurements on the SSS and its sub-dimensions in favor of the post measurement, which validates the second hypothesis.

\subsection{Findings of the Third Hypothesis}

The third hypothesis stated that: "there are no statistically-significant differences between the scores of the experimental group on the SSS in the pre and post and follow-up tests." To validate this hypothesis, the researcher used Wilcoxon (W) Test to detect the significant difference between the averages of scores ranks of the small groups. Table 7 shows the findings of this procedure:

Table 7. Wilcoxon (W) test for the detection of significant differences between the averages of scores ranks of the experimental group in the pre and post tests on the SSS

\begin{tabular}{ccccccc}
\hline SSS & $\begin{array}{c}\text { The Post and Follow-up } \\
\text { Measurement }\end{array}$ & No. & $\begin{array}{c}\text { Average of } \\
\text { Ranks }\end{array}$ & Total Ranks & Z Value & Significant \\
\hline \multirow{3}{*}{ After Social } & Negative Ranks & Zero & & & & \\
Engagement & Positive Ranks & Zero & Zero & Zero & & Insignificant \\
& Equivalence & 3 & Zero & Zero & Zero & \\
& Total & 3 & & & & \\
After Social & Negative Ranks & Zero & & Zero & & Insignificant \\
Communication & Positive Ranks & Zero & Zero & Zero & Zero & \\
& Equivalence & 3 & Zero & & & \\
& Total & 3 & & & & Insignificant \\
& Negative Ranks & Zero & & Zero & & \\
\hline
\end{tabular}

Table 7 shows no statistically-significant differences at (.01) between the averages of scores ranks of the experimental group in the post and follow-up measurement on the SSS and its sub-dimensions, which validates 
that findings of the third hypothesis.

\section{Discussion}

In general, findings of the present study shows statistically-significant differences between the averages of the scores ranks of the experimental and control groups on the SSS after the application of the program in favor of the experimental group. These findings confirm the effectiveness of the program of the present study, as a selective program, in the development of some social skills among the experimental sample of students with Autism in the present study. The social skills of these students were enhanced after the application of the program. This finding was confirmed after the findings of the study illustrated statistically significant differences between the averages of scores ranks of the experimental group in the pre and post measurements on the SSS in favor of the experimental group.

The findings of the present study stress the need to change the perception of the teachers of students with Autism from being traditional teachers whose primary goal is to teach certain academic subjects to being basic members in the application of the effective strategies and techniques in the field of improving the cases of children with Autism. Those teachers are communicating, more than others, with those children and are more aware of their characteristics because of their academic training and practical experience. Many studies like Lerman, Vorndran, Addison, and Kuhn (2004), Gouvousis (2011), and Knox, Rue, Wildenger, Lamb, and Luiselli (2012) underlined the philosophy of teachers training on the effective strategies and techniques in teaching children with Autism. Therefore, the academic preparation of teachers of students with Autism equipped them with the basic skills to apply the effective strategies, techniques, and methods that improve the cases of these students both at the level of skills development or at the level of reducing the problem behaviors they face.

Thus, several studies stressed the need of polishing the experience of teachers in the field of practical interaction with students with Autism and improving their cases through training on some effective techniques, strategies, and methods in this area, such as the procedures of teaching natural language (Smith \& Camamrata, 1999), social stories (Howell, 2005), the system of communication by exchanging pictures (Carr \& Felce 2007; Probst \& Leppert, 2008), and training on the pivotal response (Gouvousis, 2011).

The findings of the present study can be explained in the context of stating that the use of selective programs in improving the cases of children with Autism is one of the effective steps that are concerned with applying many of the techniques that studies have proven effective in developing the skills of these children or reducing problem behaviors they suffer. This is especially relevant since there are many effective strategies in the field of Autism, which can be categorized as normal intervention strategies, which emphasize the need to make the natural environment of the child with Autism as a starting point for the application of many techniques that contribute to the improvement of his/her case, thus helping to generalize the skills acquired on the natural environment in which s/he lives, especially the school environment. The use of natural intervention strategies is an expansion of natural interactions that occur between the child and adult during daily activities, which contributes to the increase in the time spent by the child during the intervention and reduces of services in which interactions are only between the child and the service provider (Harjusola-Webb \& Robbins, 2012).

The effectiveness of the program of the present study stems from its reliance on some techniques and practices that emphasize the need to take into account the characteristics of children with Autism, which are derived from the effective strategies in this field, especially the strategies of natural communication, social stories, as well as developmental, social and pragmatic interventions which stem from the developmental characteristics of the child while teaching social behaviors in an effective process that contributes to the functional communication between him/her and the social environment. There are many studies that underline the effectiveness of the models of developmental, social, and pragmatic interventions in improving connected attention and communication capabilities among children, such as Kasari, Gulsrud, Wong, Kwon, and Locke (2010) which showed an increased frequency of behaviors of connected attention and increased frequency of behaviors of functional playing among children through teachers and parents' training on focusing on developing connected attention skills in their children, and Aldred, Green, and Adams (2004) which showed that the communicative social intervention meditated by teachers and parents is effective in reducing the severity of the symptoms of Autism.

Students with Autism have benefited, in the present study, from the interactive situations designed to get them involved in many effective activities. This helped them to expand their social skills. This was clear-cut in increasing social engagement and social communication at the verbal and non-verbal levels.

The findings of the present study also showed no statistically-significant differences between the averages of scores ranks of the experimental group in the post and follow-up measurements on the SSS, which confirms the 
continued and positive effective impact of the program of the present on the study sample of children with Autism. This can be explained in the context that this program placed great importance to the need for the practice of the activities and skills learned by the child in the natural environments, as well as helping the child generalize the skills acquired in the social environment. The program of the present study relied heavily on visual prompts that attract the attention of the child and which are considered basic in address him/her and teaching him/her different academic and social skills. This stems from the fact that visual prompts is an effective factor while dealing with children with Autism, since their ability to understand visual prompts overweighs their ability to understand the audible prompts.

\section{Recommendations}

In light of the findings of the current study, the researcher recommends a number of recommendations such as; training teachers of students with Autism on applying effective strategies to improve the cases of children with Autism, especially strategies applied in the context of the natural environment of these students. Moreover, developing a curriculum in the departments of special education in education colleges about training teachers of students with Autism on effective strategies in the field and providing them with opportunities to apply them. In addition; providing opportunities for teachers of students with Autism to attend training workshops and courses in the field of methods used in the development of the skills of these students.

\section{Acknowledgements}

This is a research project that was supported by a grant from the Research Center for the Humanities, Deanship of Scientific Research at King Saud University.

\section{References}

Aldred, C., Green, J., \& Adams, C. (2004). A new social communication intervention for children with Autism: Pilot randomised controlled treatment study suggesting effectiveness. Journal of Child Psychology and Psychiatry, 45(8), 1420-1430. http://dx.doi.org/10.1111/j.1469-7610.2004.00338.x

Al-Shammari, Al-Sertawi, \& Zidan (2003). The Saudi-Kuwaiti Standards of Childhood Autism Rating Scale, Riyadh: Arab Academy for Special Education.

Bellini, S., \& Hopf, A. (2007). The development of the Autism social skills profile: A preliminary analysis of psychometric properties. Focus on Autism and Other Developmental Disabilities, 22(2), 80-87. http://dx.doi.org/10.1177/10883576070220020801

Carr, D., \& Felce, J. (2007). The effects of PECS teaching to phase III on the communicative interactions between children with Autism and their Teachers. Journal of Autism and Developmental Disorders, 37, 724-737. http://dx.doi.org/10.1007/s10803-006-0203-1

Casenhiser, D., Shanker, S., \& Stieben, J. (2011). Learning through interaction in children with Autism: Preliminary data from a social-communication-based intervention. Autism, 17(2), 220-241. http://dx.doi.org/10.1177/1362361311422052

Chan, J. (2009). Pre-service Teacher-Implemented Social Stories ${ }^{\mathrm{TM}}$ Intervention for Students with Autism Spectrum Disorders in General Education Settings (PHD, University of Texas).

Crozier, S., \& Sileo, N. (2005). Encouraging positive behavior with social stories. An intervention for children with Autism spectrum disorders. Teaching Exceptional Children, 15(3), 26-31. http://dx.doi.org/10.1177/004005990503700603

Gouvousis, A. (2011). Teacher Implemented Pivotal Response Training To Improve Communication in Children with Autism Spectrum Disorders (PHD, Carolina University).

Gray, C. (2002). Writing social stories with Carol Gray accompanying workbook to video. Arlington; Future Horizons.

Greenspan, S., Wieder, S., Hollander, E., \& Anagnostou, E. (2007). The developmental, individual-difference, relationship-based (DIR/floortime) model approach to Autism spectrum disorders. Clinical manual for the treatment of Autism (pp. 179-209). Arlington: VA: American Psychiatric.

Hagiwara, T., \& Myles, B. (1999). A multimedia social story intervention: teaching skills to children with Autism. Focus on Autism and Other Developmental Disabilities, 14(2), 8-95. http://dx.doi.org/10.1177/108835769901400203

Harjusola-Webb, S., \& Robbins, S. (2012). The Effects of Teacher-Implemented Naturalistic Intervention on the Communication of Preschoolers With Autism. Topics in Early Childhood Special Education, 32(2), 99-110. 
http://dx.doi.org/10.1177/0271121410397060

Horn, E., Lieber, J., Sandall, S., \& Schwartz, I. (2001). Embedded learning opportunities as an instructional strategy for supporting children's learning in inclusive programs. Young Exceptional Children Monograph Series, 3, 59-70.

Howell, E. (2005). Teacher perceptions of the effectiveness of social stories and comic strip conversations for students with Autism spectrum disorders. MD, California state University.

Ivey, M., Heflin, L., \& Alberto, P. (2004). The use of social stories to promote independent behaviors in novel events for children with PDD-NOS. Focus on Autism and Other Developmental Disabilities, 19(3), 164-176. http://dx.doi.org/10.1177/10883576040190030401

Kasari, C., Gulsrud, A., Wong, C., Kwon, S., \& Locke, J. (2010). Randomized controlled caregiver mediated joint engagement intervention for toddlers with Autism. Journal of Autism and Developmental Disorders, 40(9), 1045-1056. http://dx.doi.org/10.1007/s10803-010-0955-5

Leaf, J., Oppenheim-Leaf, M., Call, N., Sheldon, J., \& Sherman, J. (2012). Comparing the teaching interaction stories to social stories for people with Autism. Journal of Applied Behavior Analysis, 45(2), 281-298. http://dx.doi.org/10.1901/jaba.2012.45-281

Lerman, D., Vorndran, C., Addison., L., \& Kuhn, S. (2044). Preparing teachers in evidence-based practices for young children with Autism. School Psychology Review, 33(4), 510-525.

Morrier, M., Hess, K., \& Heflin, J. (2011). Implementation of teacher training for teaching strategies for students with Autism spectrum disorders. Teacher Education and Special Education, 34(2), 119-132. http://dx.doi.org/10.1177/0888406410376660

Murdock, L., Cost, H., \& Tieso, C. (2007). Measurement of social communication skills of children with Autism spectrum disorders during interactions with typical peers. Focus on Autism and Other Developmental Disabilities, 22(3), 160-172. http://dx.doi.org/10.1177/10883576070220030301

Pring L., Ryder, N., Crane, L., \& Hermelin, B. (2012). Creativity in savant artists with Autism. Autism, 16(1), 45-57.

Probst, P., \& Leppert, T. (2008). Brief Report: Outcomes of a Teacher Training Program for Autism Spectrum Disorders. Journal of Autism and Developmental Disorders, 38, 1791-1796. http://dx.doi.org/10.1007/s10803-008-0561-y

Scattone, D., Wilczynski, S., Edwards, R., \& Rabian, B. (2002). Decreasing disruptive behaviors of children with Autism using social stories. Journal of Autism and Developmental Disorders, 32(6), 535-543. http://dx.doi.org/10.1023/A:1021250813367

Smith, A., \& Camarata, S. (1999). Using Teacher-Implemented Instruction to Increase Language Intelligibility of Children with Autism. Journal of Positive Behavior Interventions, 1(3), 141-151. http://dx.doi.org/10.1177/109830079900100302

Stahmer, A. (2007a). The basic structure of community early intervention programs for children with Autism: Provider descriptions. Journal of Autism and Developmental Disorders, 37, 1344-1354. http://dx.doi.org/10.1007/s10803-006-0284-x

Suhrheinrich, J. (2011). Training Teachers to Use Pivotal Response Training With Children With Autism: Coaching as a Critical Component. Teacher Education and Special Education, 34(4), 339-349. http://dx.doi.org/10.1177/0888406411406553

Walker, D., Harjusola-Webb, S., Bigelow, K., Small, C., \& Kirk, S. (2004). Forming research partnerships to promote communication for infants and toddlers in child care. Young Exceptional Children Monograph Series, 6, 69-81.

\section{Copyrights}

Copyright for this article is retained by the author(s), with first publication rights granted to the journal.

This is an open-access article distributed under the terms and conditions of the Creative Commons Attribution license (http://creativecommons.org/licenses/by/3.0/). 